\title{
DISTANCE OBJECT TEST TYPE FOR CHILDREN
}

BY

\author{
F. E. Preston, D.O.M.S.
}

WANSTEAD

WHEN preparing this children's chart last winter I noticed that if the chart were placed sufficiently away from me the square on the 6/6 line lost its angles and appeared to be more or less round. I was not conscious then of the fact that the Greek mathematical friend of our youth, Euclid, 300 B.C., was familiar with this and as a matter of fact in his observations regarding it we have the first visual test on record. A translation of what he wrote is as follows :-

Rectangular magnitudes when seen from a distance become peripheries (or curves). Let the right angled figure $B \Gamma$ be elevated and seen from a distance. Then since each visible thing has a

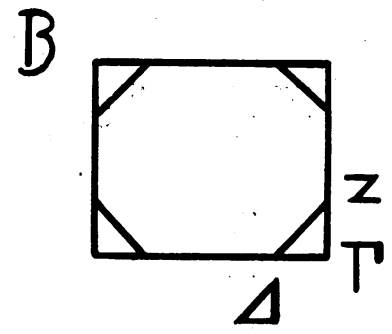

certain measure of distance at which it can no longer be seen, the angle $\Gamma$ does not appear, and only the points $\Delta Z$ are seen. This will happen equally in the case of the three remaining angles. Thus the whole will appear to be a periphery (or curve).

Except for the mentioning of mustard seeds and other tiny seeds being used in testing visual acuity, history gives us little further information until the time of that famous English experimental philosopher, Robert Hooke (1635-1703). His optical investigations led him to adopt in an imperfect form the undulatory theory of light and he made independent observations on diffraction. However, it was his interest in the heavenly bodies that brought to his notice that two of these must be separated by nearly 60 seconds if they are to be recognised by the naked eye and it was this observation which has been the basis of practically all test charts since his day. Though 60 seconds has been accepted as the angle of visual acuity yet many people can see images separated when the angle is as small as 24 seconds. If we assume that the posterior nodal point is $15.6 \mathrm{~mm}$. from the retina, then an angle of 24 seconds corresponds with a distance between the images at the retina of 
$.0018 \mathrm{~mm}$. The diameter of a cone at the macula is about $\cdot 002 \mathrm{~mm}$. so that there is an interesting relationship between the limit of perception and the anatomical structure of the retina.

It was Snellen in 1862 who first prepared letters, the component parts of which subtend an angle of 1 minute at 6 metres while the whole letter subtends an angle of 5 minutes. Although we often speak of this test made at 6 metres as being an infinity test, yet at this distance we actually use one prism dioptre of convergence and 0.16 dioptre of accommodation. An infinity test would, of course, have to be at infinity but I think if test charts were placed 8 metres away, we might regard the amount of convergence and accommodation at that distance as being negligible. Since most of us test at 6 metres we ought to bear these facts in mind when some of our patients complain that they can see aeroplanes better in the sky when they remove their distance glasses. Notwithstanding these imperfections the Snellen test has by its popularity and its continued use shown itself to be of great practical value.

A glance at the accompanying diagram will demonstrate the one and five principle, as it is sometimes called, on which a Snellen letter is constructed. I have endeavoured to produce a children's chart with drawings of familiar objects built up on the same

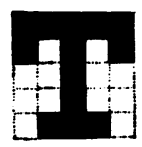

principle. The necessity for such a chart came to me when I realised that we cannot expect a child to see comfortably the print in the present day school books if his visual acuity for distance is not $6 / 12$ or better. What then can we say about the child who cannot yet read but is doing handicraft in his kindergarten class which requires just as much visual acuity ? How can we be certain that he can get $6 / 12$ or better? The familiar children's chart with horse, dog, cat, etc. can only give us a vague idea of a child's vision. How vague that idea is can be realised if we compare the chart with a Snellen's by means of a No. 1 Evans occluding glass. The former chart, however, makes no pretence of accuracy and there is no indication of the value of its objects. Unfortunately, some children's charts, with no more claim to precision, do actually bear Snellen $\frac{\mathrm{I}}{\mathrm{d}}$ values and are positively misleading. At present there are only a few children's charts on the market which accurately conform to the Snellen principle. Amongst these might be mentioned the $\mathrm{E}$ chart introduced as far back as 1885 by Albini and in later times by Bishop Harman, and the "broken-ring" 


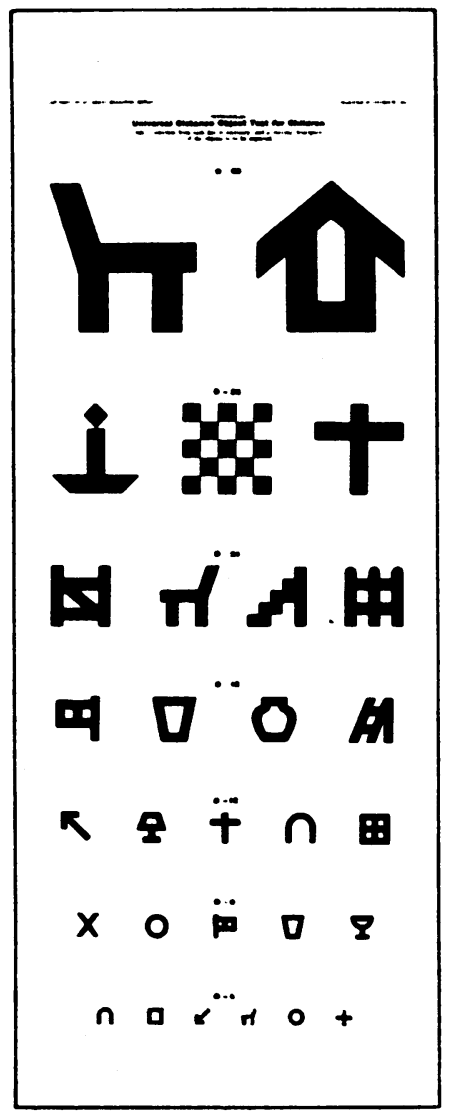

chart, which was the work of Landolt and was popularised by the Egyptian Government. As a matter of fact these charts were mainly intended for illiterates, and oculists who make use of them can hardly expect them to be interesting to children or easy to use with them.

The trial chart I had printed contained 32 test objects and was tried out at school clinics in different parts of the country. In the

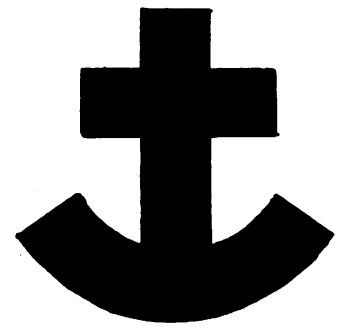


present one only those objects have been retained which were most easily interpreted by the greatest number of children. Some objects which might seem to be very familiar to adults had to be rejected. For instance, an anchor which was easily recognised by boys presented difficulties to girls and had to be discarded. The objects retained are either easy to interpret or else capable of a varied interpretation so that the test is an estimate of the child's visual acuity and not of his intelligence.

Though the work is independent on my part yet I now find that the idea of an object test chart on the strictly Snellen principle is by no means original.

\title{
ARGYROSIS OF CONJUNCTIVA, CORNEA AND TEAR-SAC
}

BY

\author{
Professor Arnold Loewenstein, M.D. \\ (FROM THE DEPARTMENT OF OPHTHALMOLOGY, UNIVERSITY OF \\ OF GLASGOW. PROF. A. J. BALLANTYNE)
}

THE deposition of silver particles on the conjunctiva is not at all rare. In countries where trachoma is endemic the use of silver drops is practised regularly, even without medical prescription, because of the relief experienced. One case is reported of a Czech farmer's wife who carried on treatment for twenty-two years (Knapová and Bruckner, 1922). Many oculists will be surprised at the length of time certain patients are using their prescriptions, the following being an example. A woman, aged 72 years, with cataract, incipient in one and more advanced on the other eye, was given argyrol ointment to be used for four days prior to operation. When she returned a year later she had a marked argyrosis, and it was discovered that she had used the ointment daily for the whole period. Successful intracapsular extraction failed to reveal any silver in the lens capsule.

Argyrosis of the conjunctiva arises not only after local use of silver, but also when this is administered orally and intravenously (Salus, 1917, Ascher, 1924), or in industrial diseases (Subal, Freyler, 1936), following treatment of nasal sinuses and after the use of silver to dye the beard, etc.

While argyrosis of the conjunctiva is frequent, corneal argyrosis is rarely mentioned (Ascher, Knapová and Bruckner, Vogt, Freyler, Kotsuka). My impression is that corneal argyrosis has been overlooked because it is not clinically conspicuous. 